\title{
Expression and Level of Test Anxiety in a Sample of Elementary Students
}

\author{
Patricia A. Lowe ${ }^{1}$ \\ ${ }^{1}$ Department of Educational Psychology, University of Kansas, Lawrence, Kansas, USA \\ Correspondence: Patricia A. Lowe, Department of Educational Psychology, University of Kansas, Lawrence, KS, \\ 66045, USA. Tel: 1-785-864-9710. E-mail: tlowe@ku.edu
}

Received: October 14, 2018

Accepted: November 18, 2018

Online Published: February 26, 2019

doi:10.5539/ies.v12n3p1

URL: https://doi.org/10.5539/ies.v12n3p1

\begin{abstract}
This study examined the expression and level of test anxiety in a sample of 1221 elementary school students. The Test Anxiety Scale for Elementary Students (TAS-E), a new multidimensional measure developed based on recent conceptualizations of the test anxiety construct, was administered to elementary school-age students. The TAS-E consists of four test anxiety (Physiological Hyperarousal, Social Concerns, Task Irrelevant Behaviors, and Worry) subscales and a Total Test Anxiety scale. The results of four multi-group confirmatory factor analyses and latent mean analyses supported invariance between groups in the four multi-group comparisons conducted and found grade and gender differences in the level and expression of test anxiety among elementary students in grades 2-5 on the TAS-E. This is the first measurement invariance study to include students as young as grade 2 on a new multidimensional measure of test anxiety. Implications of the findings of the study for mental health professionals and educators who work with elementary school-age students are discussed.
\end{abstract}

Keywords: test anxiety, grade differences, gender differences, elementary school students

\section{Introduction}

Test anxiety is general anxiety students experience in testing situations (Spielberger, Gonzalez, Taylor, Algaze, \& Anton, 1978; Taylor, 1956) and is a major problem for elementary and secondary students (Putwain \& Pescod, 2018; Sena, Lowe, \& Lee, 2008). Estimated prevalence rates of test anxiety range from $10 \%$ to $40 \%$ among the student population (Gregor, 2005), with high levels of test anxiety reported to be approximately $15 \%$ to $22 \%$ in the student population (Putwain \& Daly, 2014; Thomas, Cassady, \& Finch, 2017). Test anxiety is reported to persist over time, barring no interventions (Weems et al., 2015; Yeo, Goh, \& Liem, 2016), and it is related to negative phenomena (Szafranski, Barrera, Norton, 2012), including poorer standardized test and classroom performance (Chapell et al., 2005; von der Embse, Jester, Roy, \& Post, 2018), problems with working memory resources (Owens, Stevenson, Hadwin, \& Norgate, 2014), and school dropout (Cizek \& Berg, 2006). Therefore, it would be important to identify those students who are test anxious, so intervention strategies can be implemented to decrease their test anxiety.

\subsection{Test Anxiety Scale for Elementary Students}

The Test Anxiety Scale for Elementary Students (TAS-E) is a new multidimensional measure of test anxiety and is designed specifically for the U.S. elementary student population.

Lowe, Grumbein, and Raad (2011) conducted exploratory and confirmatory factor analyses on the responses of elementary students. Through factor analyses, Lowe and colleagues found evidence to support a four-factor structure with a higher-order factor for the TAS-E. The four test anxiety factors identified were Physiological Hyperarousal (physical symptoms associated with test anxiety), Social Concerns (concerns of significant others' reactions to one's poor test performance), Task Irrelevant Behaviors (avoidance and fidgety behaviors one experiences in testing situations), and Worry (worrisome thoughts one has about failing exams). A higher-order factor, the Total Test Anxiety factor, a measure of overall test anxiety, was also found.

The TAS-E is based on recent conceptualizations of the test anxiety construct and it stands out from other measures of test anxiety because it is new, with new items and new norms (most test anxiety measures are more than 38 years old and were developed for adults, Anderson \& Sauser, 1995), and it assesses students beginning in second grade (Lowe et al., 2011). Because it assesses students beginning in grade 2, it would be important to examine grade and 
gender differences in the level and expression of test anxiety experienced, especially among younger elementary students, as no new measure of test anxiety based on recent conceptualizations of the test anxiety construct has been developed for and includes second grade students.

\subsection{Grade and Gender Differences and Test Anxiety}

Grade differences in test anxiety have been reported, with a substantial increase in test anxiety found in elementary students from grades 3 to 5 (Hembree, 1988), but these grade differences have been reported at the total test anxiety level, not the dimensional level. In addition, there is a dearth of information about test anxiety in students in grade 2, although Seymour Sarason et al. (as cited in Hill, 1972) have stated that test anxiety can be found in second grade students.

Examination of the anxiety literature may be helpful in understanding grade/age-related differences in test anxiety, as test anxiety has been defined as general anxiety in testing situations (Spielberger et al., 1978; Taylor, 1956). Research has suggested that there are age differences in anxiety patterns in children (Dacey \& Fiore, 2000; Warren \& Sroufe, 2004; Weems, 2008; Westenberg, Siebelink, \& Treffers, 2001). Dacey and Fiore (2000) stated that these age-related differences in the expression of anxiety are impacted by the cognitive development of children, where their cognitive abilities become more abstract and awareness of their environment becomes more acute with age, suggesting that cognitive (i.e., worry) symptoms of anxiety or test anxiety may actually increase with an increase in children's age. For example, children between the ages of 9 and 11 are reported to worry about school failure (Dacey \& Fiore, 2000) and the worry component of test anxiety is defined as students' concerns about failing tests. In addition, as children become more aware of their environment with an increase in age, they may become more cognizant of their observable (e.g., jittery, restless, and avoidant) behaviors in situations where they may feel threatened, such as testing situations. Therefore, task-irrelevant behaviors, a component of test anxiety, which includes jittery, restless, and avoidant behaviors, may also increase with an increase in children's age. Based on Dacey and Fiore's (2000), Warren and Sroufe's (2004), Weems' (2008), and Westenberg et al.'s (2001) work in the field of anxiety, it is possible that grade differences in the worry and task-irrelevant behavior components of test anxiety may be found, with older elementary school students reporting higher levels of worry and task-irrelevant behaviors than younger elementary school students.

Gender differences have been reported in the elementary student population on measures of test anxiety (Nyroos, Korhonen, Peng, \& Linnanmaki, 2015; von der Embse et al., 2018). Research has shown that females reported more test anxiety symptoms than males (Nyroos et al., 2015; von der Embse et al., 2018). Zeidner (1998) has indicated that these gender differences reported are larger for the emotionality (physiological hyperarousal) component than the worry component when traditional measures of test anxiety are used. Traditional measures of test anxiety include only two components of test anxiety, an emotionality component and a worry component, based on Liebert and Morris' (1967) conceptualization of the test anxiety construct and Spielberger et al.'s (1978) work in the development of the Test Anxiety Inventory (Spielberger, 1980). However, there have been some studies where no gender differences were found on the worry component of test anxiety when these two dimensions of test anxiety were the only components examined (Zeidner \& Nevo, 1992).

Before grade and gender differences can be explored on new and existing measures, tests of measurement invariance need to be conducted. Measurement invariance is a technique used to determine whether the test scores of individuals in the different groups being compared are on the same measurement scale (Reise, Widaman, \& Pugh, 1993). Only when test scores are on the same measurement scale, group comparisons can be made. In the past, many researchers neglected to test for invariance before examining group differences and therefore, the results reported by these researchers may not be accurate. A measurement invariance study has not been conducted on a measure of test anxiety based on recent conceptualizations of the test anxiety construct and includes students in second grade.

The purpose of the present study was to examine the level and expression of test anxiety in a sample of U.S. elementary students on a new multidimensional measure of test anxiety based on recent conceptualizations of the test anxiety construct. More specifically, grade and gender differences were explored on the TAS-E in U.S. students in grades 2-5. This is the first study to the author's knowledge to examine grade and gender differences using measurement invariance on a new multidimensional measure of test anxiety developed in the United States and designed specifically for the elementary student population that also includes students as young as grade 2 . The research questions for the current study follow:

1) Is the test anxiety construct similar across grade and gender in a sample of elementary students on the TAS-E?

2) Do grade (students in grades 2-3, students in grades 4-5) differences exist on the TAS-E in a sample of elementary students? 
3) Do gender (male, female) differences exist on the TAS-E in a sample of elementary students in grades 2-5?

\section{Method}

\subsection{Participants}

The participants for the present study included 1221 elementary students, $600(49.1 \%)$ males and $621(50.9 \%)$ females. The students ranged in age from 7 to $12(M=9.41, S D=1.19)$ and were in grades $2-5(M=3.62, S D=$ 1.10). Two hundred and thirty-two (19.0\%) second graders, 328 (26.9\%) third graders, 335 (27.4\%) fourth graders, and $326(26.7 \%)$ fifth graders made up the sample. Ethnic distribution of the sample included African American (2.2\%), Asian (.5\%), Hispanic (2.5\%), Multi-racial (12.9\%), Native American (3.4\%), and White (78.5\%) elementary students. Students were recruited from 19 elementary schools. The elementary school students resided in the Midwestern region of the United States.

\subsection{Instrument}

The TAS-E was used in the present study. The TAS-E is a 30 item, multidimensional measure based on recent conceptualizations of the test anxiety construct. The TAS-E consists of four test anxiety (Physiological Hyperarousal, Social Concerns, Task Irrelevant Behaviors, and Worry) subscales and a Total Test Anxiety scale. The Physiological Hyperarousal subscale (9 items) assesses the physical symptoms associated with test anxiety and the Social Concerns subscale (6 items) measures concerns about parents, teachers and peers if one does not do well on a test. The Task Irrelevant Behaviors subscale ( 8 items) measures fidgety and avoidance behaviors and the Worry subscale ( 7 items) assesses the worrisome thoughts about failing tests and the repercussions associated with failing. The Total Test Anxiety scale score is determined by summing the raw scores from the four test anxiety subscales and is a measure of overall test anxiety. Cronbach coefficient alphas for the four test anxiety subscale scores and the Total Test Anxiety scale scores reported in an earlier study ranged from .78 to .92 (Lowe et al., 2011). Validity evidence for the TAS-E scores has been reported (Lowe et al., 2011).

\subsection{Procedures}

Parental consent was obtained prior to the study and student assent was obtained before the TAS-E and in some cases, other measures were administered to the elementary students. Students were administered the measure(s) in large groups in their schools. Test administrators followed standardized test procedures in the administration of the measure(s). The sample used in the present study is part of the norming sample of the TAS-E.

\section{Results}

\subsection{Confirmatory Factor Analyses}

Analyses for the present study were conducted with Mplus, Version 7.11 (L. K. Muthén, \& B. O. Muthén, 1998-2013). Single-group confirmatory factor analyses (CFAs) were performed for each of eight different groups. The eight different groups included students in grades 2-3, students in grades 4-5, males, females, female students in grades 2-3, male students in grades 2-3, female students in grades $4-5$, and male students in grades $4-5$. The robust weighted least squares, WLSMV, estimator served as the parameter estimator in these analyses due to univariate and multivariate non-normality and the categorical nature of the TAS-E response options (see Flora \& Curran, 2004; Wirth \& Edwards, 2007).

$\mathrm{Hu}$ and Bentler's (1999) guidelines were used to determine a good and an adequate model fit to the data. A model was considered to be a good fit if the comparative fit index (CFI) value and the Tucker-Lewis index (TLI) value were equal to or greater than .95 and the root mean square error of approximation (RMSEA) value was less than .06. A model was considered to be an adequate model fit if the CFI value and the TLI value were greater than .90 and the RMSEA value was less than .08 .

The results of the single-group CFAs for the eight different groups are presented in Table 1. A good model fit was found for students in grades 2-3, students in grades 4-5, males, females, and female students in grades 4-5. An adequate model fit was reported for male students in grades 2-3, female students in grades 2-3, and male students in grades 4-5. 
Table 1. Summary of the fit indexes from the single-group confirmatory factor analyses for eight different groups on the test anxiety scale for elementary students

\begin{tabular}{llllll}
\hline Groups & WLSMV $\chi^{2}$ & df & CFI & TLI & RMSEA [90\% CI] \\
\hline Males & $885.048 * * * *$ & 399 & .957 & .953 & $.045[.041, .049]$ \\
Females & $870.905 * * * *$ & 399 & .964 & .961 & $.044[.040, .048]$ \\
Students in Grades 2-3 & $806.370 * * * *$ & 399 & .963 & .960 & $.043[.038, .047]$ \\
Students in Grades 4-5 & $899.856 * * * *$ & 399 & .964 & .960 & $.044[.040, .047]$ \\
Males Grades 2-3 & $639.666 * * * *$ & 399 & .952 & .948 & $.048[.041, .055]$ \\
Females Grades 2-3 & $657.539 * * * *$ & 399 & .953 & .949 & $.047[.040, .053]$ \\
Males Grades 4-5 & $703.801 * * * *$ & 399 & .948 & .944 & $.048[.042, .053]$ \\
Females Grades 4-5 & $628.264 * * * *$ & 399 & .966 & .963 & $.042[.036, .048]$ \\
\hline
\end{tabular}

Note. WLSMV $\chi 2=$ robust mean-and-variance adjusted chi-square; $d f=$ degrees of freedom; $\mathrm{CFI}=$ comparative fit index; TLI $=$ Tucker-Lewis index; RMSEA $=$ root mean square error of approximation; $90 \% \mathrm{CI}=90 \%$ confidence interval; $* * * * p<.0001$.

\subsection{Composite Reliabilities}

Composite reliability estimates were computed for the eight different groups on each of the four subscales of the TAS-E. The range of these composite reliability estimates for the four TAS-E subscales for each of the eight different groups is presented in Table 2. The overall range for each of the eight different groups on the four TAS-E subscales was .84 to .93 .

Table 2. Composite reliability ranges for the eight different groups on the four subscales of the test anxiety scale for elementary students

\begin{tabular}{lc}
\hline Groups & Composite Reliabilities \\
\hline Males & $.85-.92$ \\
Females & $.87-.92$ \\
Students in Grades 2-3 & $.85-.91$ \\
Students in Grades 4-5 & $.86-.93$ \\
Males Grades 2-3 & $.86-.91$ \\
Females Grades 2-3 & $.84-.92$ \\
Males Grades 4-5 & $.84-.93$ \\
Females Grades 4-5 & $.87-.92$ \\
\hline
\end{tabular}

\subsection{Multi-Group Confirmatory Factor Analyses}

Tests of measurement invariance followed. Multi-group CFAs were performed across males and females, students in grades 2-3 and students in grades 4-5, male students in grades 2-3 and female students in grades 2-3, and male students in grades 4-5 and female students in grades 4-5. Chen's (2007) criteria, a change in the CFI, $\Delta C F I,<.01$ and a change in the RMSEA, $\triangle \mathrm{RMSEA},<.015$, were used to determine whether configural, metric, and scalar invariance seemed tenable for the four multi-group comparisons. The results of the four multi-group comparisons indicated configural, metric, and scalar invariance was supported, as the $\triangle \mathrm{CFI}$ and $\triangle \mathrm{RMSEA}$ were within Chen's criteria for each test of invariance conducted (see Table 3). 
Table 3. Tests of invariance across grade and gender on the test anxiety scale for elementary students

\begin{tabular}{|c|c|c|c|c|c|c|c|c|}
\hline Groups & WLSMV $\chi 2$ & $d f$ & $\Delta \mathrm{WLSMV} \chi 2$ & $\Delta d f$ & CFI & $\Delta \mathrm{CFI}$ & RMSEA [ $90 \% \mathrm{CI}]$ & $\triangle \mathrm{RMSEA}$ \\
\hline \multicolumn{9}{|c|}{ Males and Females } \\
\hline 1. Configural & $1756.062 * * * *$ & 798 & & & .961 & & $.044[.042, .047]$ & \\
\hline 2. Metric & $1654.571^{* * * *}$ & 824 & $42.223^{*}$ & 26 & .966 & .005 & $.041[.038, .043]$ & .003 \\
\hline 3. Scalar & $1832.517 * * * *$ & 910 & $252.709 * *$ & 86 & .962 & .004 & $.041[.038, .043]$ & .000 \\
\hline \multicolumn{9}{|c|}{ Grades 2-3 and 4-5 } \\
\hline 1. Configural & $1706.156^{* * * *}$ & 798 & & & .964 & & $.043[.040, .046]$ & \\
\hline 2. Metric & $1565.497 * * * *$ & 824 & 22.462 & 26 & .970 & .006 & $.038[.035, .041]$ & .005 \\
\hline 3. Scalar & $1705.746^{* * * *}$ & 910 & $189.840 * *$ & 86 & .968 & .002 & $.038[.035, .041]$ & .000 \\
\hline \multicolumn{9}{|c|}{ Males \& Females Grades 2-3 } \\
\hline 1. Configural & $1295.326 * * * *$ & 798 & & & .953 & & $.047[.042, .052]$ & \\
\hline 2. Metric & $1254.655^{* * * *}$ & 824 & 36.995 & 26 & .959 & .006 & $.043[.038, .048]$ & .004 \\
\hline 3. Scalar & $1351.958 * * * *$ & 910 & $125.779 * *$ & 86 & .958 & .001 & $.042[.037, .046]$ & .001 \\
\hline \multicolumn{9}{|c|}{ Males \& Females Grades 4-5 } \\
\hline 1. Configural & $1331.084 * * * *$ & 798 & & & .958 & & $.045[.041, .049]$ & \\
\hline 2. Metric & $1316.523 * * * *$ & 824 & $40.427 *$ & 26 & .961 & .003 & $.043[.038, .047]$ & .002 \\
\hline 3. Scalar & $1480.566^{* * * *}$ & 910 & $246.746 * *$ & 86 & .955 & .006 & $.044[.039, .048]$ & .001 \\
\hline
\end{tabular}

Note. WLSMV $\chi 2$ = robust mean-and-variance adjusted chi-square; $d f=$ degrees of freedom; $\Delta \mathrm{WLSMV} \chi^{2}=$ change in the robust mean-and-variance adjusted chi-square; $\Delta d f=$ change in degrees of freedom; CFI $=$ comparative fit index; $\triangle \mathrm{CFI}=$ change in the comparative fit index; RMSEA = root mean square error of approximation; $90 \% \mathrm{CI}=90 \%$ confidence interval; $\triangle \mathrm{RMSEA}=$ change in the root mean square error of approximation; ${ }^{*} p<.05,{ }^{* *} p<.01, * * * * p<.0001$

\subsection{Latent Mean Analyses}

Latent mean analyses were performed for each of the four multi-group comparisons on the TAS-E (see Table 4). The advantage of conducting latent means analyses is that latent means do not contain measurement error, whereas observed scores do. In addition, effect sizes, Cohen's (1988) ds, were computed. Students in grades 4-5 reported more task irrelevant behaviors and worry symptoms than students in grades 2-3, with small effect sizes. Females, female students in grades 2-3, and females in grades 4-5 reported more physiological hyperarousal, task irrelevant behaviors, and worry symptoms than males, male students in grades $2-3$, and male students in grades $4-5$, respectively, with small effect sizes. 
Table 4. Latent mean analyses and effect sizes (d) for students in grades 2-3 and 4-5 and males and females on the test anxiety scale for elementary students

\begin{tabular}{lcccc}
\hline & $\beta$ estimate & $S E$ & $p$ & $d$ \\
\hline Males and Females & & & & .42 \\
Physiological Hyperarousal & .423 & .063 & $<.001$ & .26 \\
Task Irrelevant Behaviors & .261 & .066 & $<.001$ & .04 \\
Social Concerns &. .038 & .111 & .734 & .30 \\
Worry & .299 & .065 & $<.001$ & .03 \\
Students in Grades 2-3 and 4-5 & & & .48 \\
Physiological Hyperarousal & .032 & .066 & .627 & .18 \\
Task Irrelevant Behaviors & .478 & .066 & $<.001$ & .31 \\
Social Concerns &. .183 & .122 & .133 & .39 \\
Worry & .309 & .062 & $<.001$ & .28 \\
Males and Females in Grades 2-3 & & & .11 \\
Physiological Hyperarousal & .393 & .091 & $<.001$ & .21 \\
Task Irrelevant Behaviors & .280 & .096 & $<.01$ & .469 \\
Social Concerns & .109 & .151 & $<.059$ & .46 \\
Worry & .208 & .095 & & .31 \\
Males and Females in Grades 4-5 & & & & .18 \\
Physiological Hyperarousal & .455 & .086 & .001 & .41 \\
Task Irrelevant Behaviors & .306 & .162 & .093 & \\
Social Concerns & -.180 & .405 & & \\
Worry & & .001 & \\
\hline
\end{tabular}

\section{Discussion and Conclusion}

Overall, the findings from the present study indicated that the test anxiety construct is relatively similar across grade and gender in a sample of U.S. elementary students in grades 2-5. To the author's knowledge this is the first study that has examined measurement invariance with a U.S. elementary student sample on a multidimensional measure based on recent conceptualizations of the test construct and developed to include students as young as second grade. This finding indicates that group comparisons can be made across grade and gender on the TAS-E in samples of elementary school-age students in grades 2-5.

Grade differences were found on the TAS-E. Students in grades 4-5 reported more task irrelevant behaviors and worry symptoms than students in grades 2-3. The clinically meaningful differences in task-irrelevant behaviors and worry in the current study appear to be in line with age-related differences discussed within the field of anxiety (Dacey \& Fiore, 2000; Warren \& Sroufe, 2004; Weems, 2008; Westenberg, Siebelink, \& Treffers, 2001) and may be related to the cognitive development of children where they become more aware of their cognitions and their environment (Dacey \& Fiore, 2000) and possibly their observable (jittery, restless, and avoidant) behaviors, with an increase in age. Evidence does exist to support an association between children's worry and their development (Vasey \& Daleiden, 1994), with worrisome thoughts becoming more pronounced and complex as children age (Muris, Merckelbach, Meesters, \& van den Brand, 2002; Vasey, Crnic, \& Carter, 1994).

Besides grade differences, gender differences were also found on the TAS-E, with females, females in grades 2-3, and females in grades 4-5 reporting more physiological hyperarousal, task irrelevant behaviors, and worry symptoms than males, males in grades 2-3, and males in grades 4-5, respectively, with small effect sizes. It is interesting to note that the physiological hyperarousal component had the largest effect size, which is in agreement with the test anxiety literature (Zeidner, 1998). Overall, these findings are in agreement with the test anxiety literature, with females reporting more test anxiety symptoms than males (Seipp \& Schwarzer, 1996; von der Embse et al., 2018).

The findings of the present study suggest that elementary school-age females and students in fourth and fifth grades are at a higher risk for test anxiety than elementary school-age males and students in second and third grades. Therefore, students who are at a higher risk may benefit from strategies to decrease their symptoms of test anxiety. Research has shown interventions to be effective in reducing the cognitive and physiological hyperarousal (emotionality) components of test anxiety (Ergene, 2003; Hembree, 1988; von der Embse, Barterian, \& Segool, 2013). Weems et al. (2015) and Yeo et al. (2016) have conducted test anxiety intervention programs with elementary students in school settings using behavioral (i.e., relaxation and exposure) and 
cognitive-behavioral (i.e., relaxation, self-talk, and study skills training) strategies, respectively, and have found significant reductions in students' test anxiety. Although these programs did not examine task irrelevant behaviors and research would need to be conducted, avoidant, restless, and jittery behaviors may also be reduced in these same programs due to the relaxation training and/or exposure components students' receive. Other potential strategies to reduce students' task-irrelevant behaviors may include coping skills training, systematic desensitization, and modeling (Ergene, 2003; Huberty \& Dick, 2006; Zeidner, 1998).

There are several limitations associated with the present study. The ethnic and regional diversity of the current study's sample was somewhat limited. The elementary student sample used in the present study was predominately White and from the Midwestern region of the United States. Therefore, replication of the current study with a more representative U.S. sample should be conducted in the future. . Another limitation of the current study was the use of only one assessment method (i.e., self-report). Although self-reports are one of the better methods to assess students' internalizing issues (Woodruff-Borden \& Leyfer, 2005), the use of other assessment techniques, such as parent and teacher behavior rating scales, parent and teacher interviews, and naturalistic observations would be helpful in corroborating the students' test anxiety reported. Other areas for future research with the TAS-E include the assessment of elementary students' performance on the TAS-E before, during, and after high-stakes testing, and other measurement invariance studies that examine test anxiety across different ethnic groups in the United States.

In sum, grade and gender differences were found among elementary students on the TAS-E. These grade and gender differences in the level and expression of test anxiety are important to examine to identify students who may be at a higher risk for test anxiety. Students in grades 4-5 had clinically meaningful higher levels of task-irrelevant behaviors and worry than students in grades 2-3 and females had clinically meaningful higher levels of physiological hyperarousal, task-irrelevant behaviors, and worry than males. These findings may provide assistance to mental health professionals and educators who work directly with elementary school-age students in identifying and directing intervention efforts to decrease children's test anxiety.

\section{References}

Anderson, S. B., \& Sauser, W. J. (1995). Measurement of test anxiety: An overview. In C. D. Spielberger, \& P. R. Vaag (Eds.), Test anxiety: Theory, assessment, and treatment (pp. 15-33). Washington, DC: Taylor \& Francis.

Brown, T. A. (2006). Confirmatory factor analysis for applied research. New York, NY: Guilford Press.

Brown, T. A. (2015). Confirmatory factor analysis for applied research (2nd ed.). New York, NY: Guilford Press.

Chapell, M. S., Blanding, Z. B., Silverstein, M. E., Takahashi, M. N. B., Newman, B., Gubi, A., \& McCain, N. (2005). Test anxiety and academic performance in undergraduate and graduate students. Journal of Educational Psychology, 97, 268-274. https://doi.org/10.1037/0022-0663.97.2.268

Chen, F. F. (2007). Sensitivity of goodness of fit indexes to lack of measurement invariance. Structural Equation Modeling, 14, 464-504. https://doi.org/10.1080/10705510701301834

Cizek, G. J., \& Burg, S. S. (2006). Addressing test anxiety in a high-stakes environment. Thousand Oaks, CA: Corwin Press.

Cohen, J. (1988). Statistical power analysis for the behavioral sciences (2nd ed.). Hillsdale, NJ: Lawrence Erlbaum Associates.

Dacey, J. S., \& Fiore, L. B. (2000). Your anxious child: How parents and teachers can relieve anxiety in children. San Francisco, CA: Jossey-Bass.

Ergene, T. (2003). Effective interventions on test anxiety reduction: A meta-analysis. School Psychology International, 24, 313-328. https://doi.org/10.1177/01430343030243004

Gregor, A. (2005). Examination anxiety: Live with it, control it or make it work for you? School Psychology International, 26, 617-635. https://doi.org/10.1177/0143034305060802

Hembree, R. (1988). Correlates, causes, effects, and treatment of test anxiety. Review of Educational Research, 58, 47-77. https://doi.org/10.3102/00346543058001047

Hill, K. T. (1972). Anxiety in the evaluative context. In W. Hartup (Ed.), The young child (Volume 2, pp. 225-263). Washington, DC: National Association for the Education of Young Children.

Hu, L., \& Bentler, P. M. (1999). Cutoff criteria for fit indexes in covariance structure analysis: Conventional 
criteria versus new alternatives. Structural Equation Modeling, 6, 1-55. https://doi.org/10.1080/10705519909540118

Huberty, T. J., \& Dick, A. C. (2006). Performance and test anxiety. In G. G. Bear, \& K. M. Minke (Eds.), Children's needs III: Development, prevention, and intervention (pp. 281-291). Bethesda, MD: The National Association of School Psychologists.

Kline, R. B. (2011). Principles and practice of structural equation modeling (3rd ed.). New York, NY: Guilford.

LeBeau, R. T., Glenn, D., Liao, B., Wittchen, H., Beesdo-Baum, K., Ollendick, T., \& Craske, M. G. (2010). Specific phobia: A review of DSM-IV specific phobia and preliminary recommendations for DSM-V. Depression and Anxiety, 27, 148-167. https://doi.org/10.1002/da.20655

Liebert, R. M., \& Morris, L. W. (1967). Cognitive and emotional components of test anxiety: A distinction and some initial data. Psychological Reports, 20, 975-978. https://doi.org/10.2466/pr0.1967.20.3.975

Lowe, P. A., Grumbein, M. J., \& Raad, J. M. (2011). Examination of the psychometric properties of the Test Anxiety Scale for Elementary Students (TAS-E) scores. Journal of Psychoeducational Assessment, 29, 503-514. https://doi.org/10.1177/0734282910395894

Meredith, W. (1993). Measurement invariance, factor analysis, and factorial invariance. Psychometrika, 58, 525-542. https://doi.org/10.1007/BF02294825

Muris, P., Merckelbach, H., Meesters, C., \& van den Brand, K. (2002). Cognitive development and worry in normal children. Cognitive Therapy and Research, 26, 775-787. https://doi.org/10.1023/A:1021241517274

Muthén, L. K., \& Muthén, B. O. (1998-2013). Mplus version 7.11. Los Angeles, CA: Author.

Nyroos, M., Korhonen, J., Peng, A., \& Linnanmaki, K. (2015). Cultural and gender differences in experiences and expression of test anxiety among Chinese, Finnish, and Swedish grade 3 pupil. International Journal of School \& Educational Psychology, 3, 37-48. https://doi.org/10.1080/21683603.2014.915773

Owens, M., Stevenson, J., Hadwin, J. A., \& Norgate, R. (2014). When does anxiety help or hinder cognitive test performance? The role of working memory capacity. British Journal of Psychology, 105, 92-101. https://doi.org/10.1111/bjop.12009

Putwain, D. W., \& Daly, A. L. (2014). Test anxiety prevalence and gender differences in a sample of English $\begin{array}{lllll}\text { secondary school students. } & \text { Educational }\end{array}$ https://doi.org/10.1080/03055698.2014.953914

Putwain, D. W., \& Pescod, M. (2018). Is reducing uncertain control the key to successful test anxiety intervention for secondary school students? Findings from a randomized control trial. School Psychology Quarterly, 33, 283-292. https://doi.org/10.1037/spq0000228

Reise, S. P., Widaman, K. F., \& Pugh, R. H. (1993). Confirmatory factor analysis and item response theory: Two approaches for exploring measurement invariance. Psychological Bulletin, 114, 552-566. https://doi.org/10.1037/0033-2909.114.3.552

Seipp, B., \& Schwarzer, C. (1996). Cross-cultural anxiety research: A review. In C. Schwarzer \& M. Zeidner (Eds.), Stress, anxiety, and coping in academic settings (pp. 13-68). Tubingen, Germany: Francke-Verlag.

Sena, J. D. W., Lowe, P. A., \& Lee, S. W. (2007). Significant predictors of test anxiety among students with and without learning disabilities. Journal of Learning Disabilities, 40, 360-376. https://doi.org/10.1177/00222194070400040601

Spielberger, C. D., Gonzalez, H. P., Taylor, C. J., Algaze, B., \& Anton, W. D. (1978). Examination stress and test anxiety. In C.D. Spielberger \& I.G. Sarason (Eds.), Stress and anxiety (Vol. 5, pp. 167-191). Washington, DC: Hemisphere/Wiley.

Szafranski, D. D., Barrera, T. L., \& Norton, P. J. (2012). Test Anxiety Inventory: 30 years later. Anxiety, Stress, \& Coping, 25, 667-677. https://doi.org/10.1080/10615806.2012.663490

Taylor, J. A. (1956). Drive theory and manifest anxiety. Psychological Bulletin, 53, 303-328.

Thomas, C. L., Cassady, J. C., \& Finch, W. H. (2017). Identifying severity standards on the Cognitive Test Anxiety Scale: Cut score determination using latent class and cluster analysis.

Vasey, M. W., \& Daleiden, E. L. (1994). Worry in children. In G. C. L. Davey \& F. Tallis (Eds.), Worrying: Perspectives on theory, assessment, and treatment (pp. 185-207). Chichester, UK: Wiley. 
Vasey, M. W., Crnic, K. A., \& Carter, W. G. (1994). Worry in childhood: A developmental perspective. Cognitive Therapy and Research, 18, 529-549. https://doi.org/10.1007/BF02355667

Von der Embse, N., Barterian, J., \& Segool, N. (2013). Test anxiety interventions for children and adolescents: A systematic review of treatment studies from 2000-2010. Psychology in the Schools, 50, 57-71. https://doi.org/10.1002/pits.21660

Von der Embse, N., Jester, D., Roy, D., \& Post, J. (2018). Test anxiety effects, predictors, and correlates: A 30-year meta-analytic review. Journal of Affective Disorders, 227, 483-493. https://doi.org/10.1016/j.jad.2017.11.048

Warren, S. L., \& Sroufe, L. A. (2004). Developmental issues. In T. H. Ollendick, \& J. S. March (Eds.), Phobic and anxiety disorders in children and adolescents: A clinician's guide to effective psychosocial and pharmacological interventions (pp. 92-115). New York: Oxford University Press. https://doi.org/10.1093/med:psych/9780195135947.003.0004

Weems, C. F. (2008). Developmental trajectories of childhood anxiety: Identifying continuity and change in anxious emotion. Developmental Review, 28, 488-502. https://doi.org/10.1016/j.dr.2008.01.001

Weems, C. F., Scott, B. G., Graham, R. A., Banks, D. M., Russell, J. D. Taylor, L. K., . . Mario, R. C. (2015). Fitting anxious emotion-focused interventions into the ecology of schools: Results from a test anxiety program evaluation. Prevention Science, 16, 200-210. https://doi.org/10.1007/s11121-014-0491-1

Westenberg, P. M., Siebelink, B. M., \& Treffers, P. D. A. (2001). Psychosocial developmental theory in relation to anxiety and its disorders. In W. K. Silverman, \& P. D. A. Treffers (Eds.), Anxiety disorders in children and adolescents: Research, assessment and intervention (pp. 72-89). Cambridge, UK: Cambridge University Press.

Woodruff-Borden, J., \& Leyfer, O. T. (2006). Anxiety and fear. In M. Hersen (Ed.), Clinician's handbook of child behavioral assessment (pp. 267-289). London: https://doi.org/10.1016/B978-012343014-4/50012-5

Yeo, L. S., Goh, V. G., \& Liem, G. A. D. (2016). School-based intervention for test anxiety. Child \& Youth Forum, 45, 1-17. https://doi.org/10.1007/s10566-015-9314-1

Zeidner, M. (1998). Test anxiety: The state of the art. New York, NY: Plenum Press.

Zeidner, M., \& Nevo, B. (1992). Test anxiety in examinees in a college admission testing situation: Incidence, dimensionality, and cognitive correlates. In K. A. Hagtvet, \& B. T. Johnsen (Eds.), Advances in test anxiety research (Vol. 7, pp. 288-303). Lisse, The Netherlands: Swets \& Zeitlinger.

\section{Copyrights}

Copyright for this article is retained by the author(s), with first publication rights granted to the journal.

This is an open-access article distributed under the terms and conditions of the Creative Commons Attribution license (http://creativecommons.org/licenses/by/4.0/). 